\title{
Light and scanning electron microscopic studies of the angioarchitecture of intrinsic muscle fibers of the anterior rat tongue
}

\author{
Aracy Akiko Motoyama and Ii-sei Watanabe \\ Department of Anatomy, Institute of Biomedical Sciences, University of São Paulo, \\ São Paulo, Brazil
}

(Received 25 July and accepted 5 December 2001)

\begin{abstract}
Histological and scanning electron microscopy (SEM) characteristics of the microvasculature of muscle fibers in the anterior third of the adult rat tongue are described. For light microscopy, the specimens were embedded in paraffin and frontal sections were stained with Picro-Sirius. Thick sections were obtained from Spurr embedded samples and stained with toluidine blue solution. For SEM, specimens were obtained by the corrosion cast method and fractured specimens in dimethyl sulfoxide were observed with high-resolution SEM (HRSEM). The blood vessels, enveloped with a thin layer of connective tissue, had fibers running parallel to the muscular fibers. Capillary arterioles were noted following the endomysium, but their lateral branches often ran at right angles to the fibers. The capillary beds were clearly revealed in transverse sections where the individual capillaries appeared ring-like or elliptical in shape. The nuclei of endothelial cell cores could be seen on the vessel surfaces. Collagen fibers type $I$ and III were noted in the connective tissue and in the fibrous layer of vessels. (J. Oral Sci, 43, 269-275, 2001)
\end{abstract}

Key words: blood vessels; conventional SEM; corrosion cast; HRSEM; microvascularization.

Correspondence to Dr. Ii-sei Watanabe, Department of Anatomy, Institute of Biomedical Sciences, University of São Paulo. Av. Prof. Lineu Prestes, 2415. Cep. 05508-000 São

Paulo, Brazil

Tel: $+55-11-3818-7258$

Fax: +55-11-3818-7366

E-mail address: watanabe@icb.usp.br.

\section{Introduction}

As the tongue plays an important role in mastication and deglutition and is the gustatory organ, it requires a large supply of blood compared with other muscular organs (1). The microvascular system consists of arteriolae, capillaries and venules and the sinusoids that are present in some organs such as the spleen, liver and bone marrow (2). Use of the corrosive resin cast method was primarily reported by Tanigushi et al. $(3,4)$ and Murakami $(5)$ who, using a low-viscosity resin, observed that even the complex capillary distributions and their relationships could be reproduced and observed three-dimensionally. Several authors have used this method to study the angioarchitecture of the tongues of dogs $(6,7)$, primates $(8)$, human fetuses (2), rats (9-11) and undernourished rats (12). Lametschwandtner et al. (13) reported the angioarchitecture as having a three-dimensional organization of the vessels. The corrosive vascular cast, showing the thin vascular architecture in the tissue, was useful in showing the morphologic relationships between the alteration in the vascular cast and the revascularization of the tissues (14). The capillaries have also been analyzed by examination of the fractured surface of tissues in scanning electron microscopy (SEM) with dimethyl sulfoxide method (DMSO) which has shown the three-dimensional characteristics (15-17).

The aim of this paper was to demonstrate the presence of the blood vessels in the muscular layer of the anterior third of rat's tongue, using the Mercox injection and highresolution SEM (HRSEM) methods.

\section{Materials and Methods}

Ten adult Wistar rats, weighing 200 to $250 \mathrm{~g}$, were used. 
The animals were sacrificed by intraperitoneal injection of $30 \mathrm{mg} / \mathrm{kg}$ pentobarbital sodium, and the tongues were excised carefully. For light microscopy, the anterior part of the tongue was fixed in Bouin's solution for $48 \mathrm{~h}$ at room temperature. Then the specimens were rinsed in water for $72 \mathrm{~h}$, dehydrated in a graded series of ethanol and embedded in paraffin. Frontal sections $5 \mu \mathrm{m}$ thick were cut with a microtome (Young) and stained with Picro-Sirius, so that the bundles of collagen fibers could be examined with polarized light microscopy (18). Small samples of tongue were removed and fixed in modified Karnovsky solution containing 2.5\% glutaraldehyde and 2\% paraformaldehyde in a $0.1 \mathrm{M}$ sodium phosphate buffer $(\mathrm{pH} 7.4)$ for $12 \mathrm{~h}$ at $4{ }^{\circ} \mathrm{C}$. The specimens were post-fixed in $1 \%$ osmium tetroxide solution for $2 \mathrm{~h}$ at $4^{\circ} \mathrm{C}$ and embedded in Spurr's resin (19). Thick (about $0,5 \mu \mathrm{m}$ ) sections were obtained with a Reichert Ultracut-E (C. Reichert AG, Vienna, Austria) and stained with $2 \%$ toluidine blue solution for light microscopy.

For high-resolution scanning electron microscopy (HRSEM), the samples were prepared with the aldehydeprefixed osmium-dimethyl sulfoxide (DMSO) osmium method $(15,16,20,21)$. Small blocks of tissue (3 $\mathrm{mm}$ in length) were removed from the animals and fixed in $2 \%$ buffered osmium tetroxide solution for $2 \mathrm{~h}$ at $4{ }^{\circ} \mathrm{C}$. The tissues were rinsed with distilled water and then successively immersed in $12.5 \%, 25 \%$ and $50 \%$ DMSO solution for $30 \mathrm{~min}$ each. The specimens were frozen on a metal plate, chilled with liquid nitrogen and split with a razor blade and a hammer in a freeze-fracture apparatus (TF-2, Eiko Engineering Co. Ltd., Japan). The split pieces were immediately placed in 50\% DMSO and thawed at room temperature. The tissues were rinsed with distilled water and pos-fixed in $2 \%$ osmium tetroxide solution for $2 \mathrm{~h}$ at $4{ }^{\circ} \mathrm{C}$. The specimens were washed again in distilled water and treated with $1 \%$ tannic acid solution for $2 \mathrm{~h}$ at room temperature (22). The specimens were dried in a critical-point dryer (Eiko ID-2), coated with gold-palladium in a BIO-RAD-SEM Coating System (Japan) and observed with a HRSEM (Hitachi, S-900) at $10 \mathrm{kV}$.

For scanning electron microscopy with the corrosion cast method, the thoraxes of the animals were opened to expose the heart and large vessels. The heart apex was cut off and a canula inserted via the left ventricle into the ascending aorta and fixed by ligation at the level of its descending part. Vascular perfusion with $0.9 \%$ physiological saline solution at $40^{\circ} \mathrm{C}$ was continued until the efflux of the superior vena cava became clear. The synthetic resin (Mercox ${ }^{\circledR}$ CL2-B, Dainippon Inki Chemical Co. Ltd., Tokyo, Japan) was injected under manual pressure by the corrosive resin cast method $(5,6)$. The injected specimens of the tongue were kept at room temperature for $2 \mathrm{~h}$. After they had been completely polymerized, the specimens were treated with $10 \%$ of $\mathrm{NaOH}$ solution for 5 days at room temperature (23). Two tongues were fixed with modified Karnovsky solution, freeze-fractured in liquid nitrogen and then were digested with $10 \% \mathrm{NaOH}$ for 5 days at room temperature. The other specimens were immersed in $8 \mathrm{~N}$ $\mathrm{HCl}$-collagenase solution according to the method reported by Evan et al. (24). The vascular resin casts were carefully washed in slowly flowing distilled water and dried at room temperature. The dried vascular casts were mounted on stubs with adhesive paste, coated with gold in a Balzers Union ion sputter apparatus (SCD-040) and examined under an SEM (JEOL, JSM-6100) at $10 \mathrm{kV}$.

\section{Results}

The frontal sections of the anterior third of the adults rat tongue stained by Picro-Sirius showed collagen fibers types I and III in the connective tissue and overlying the blood vessels (Fig. 1). Transverse bundles of muscle fibers, bundles of nerve fibers and a blood capillary were observed in the connective tissue. The capillary showed the external fibrous layer of collagen fibers (Fig. 2). The thick sections stained with toluidine blue showed muscle fibers enveloped by the endomysium, with peripheral oval and/or cylindrical nuclei. The blood capillaries and bundles of nerve fibers on the muscle layer connective tissue were clearly seen (Figs. 3,4). The corrosive vascular cast examined by SEM showed that the vessels penetrated the muscular layer and their gauge increased until they built up a capillary network in the area. The connective tissue of the endomysium and arterial capillaries were wound, progressing to the surface where they presented superficial capillary projections (Fig. 5). The vessels showed coils and sinuosities that followed the muscle fiber orientations (Fig. 6). The vessel

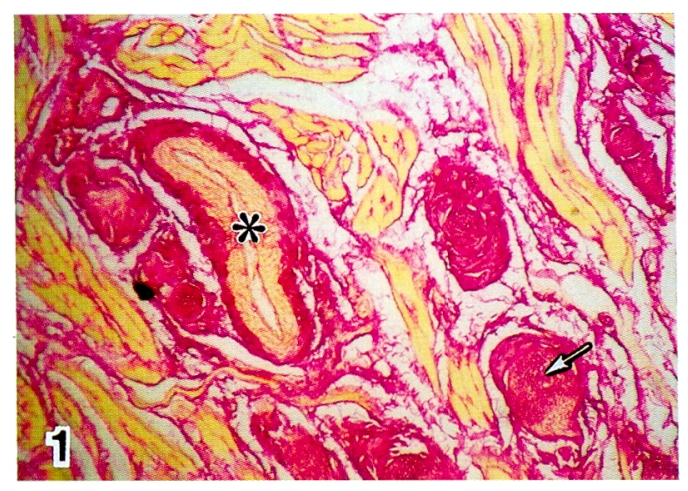

Fig. 1 Light microscopy showing the bundles of muscle fibers of the anterior third of rat tongue. The capillary $(*)$ and nervous fibers bundles (arrow) are seen. Picro-Sirius $\times 125$. 


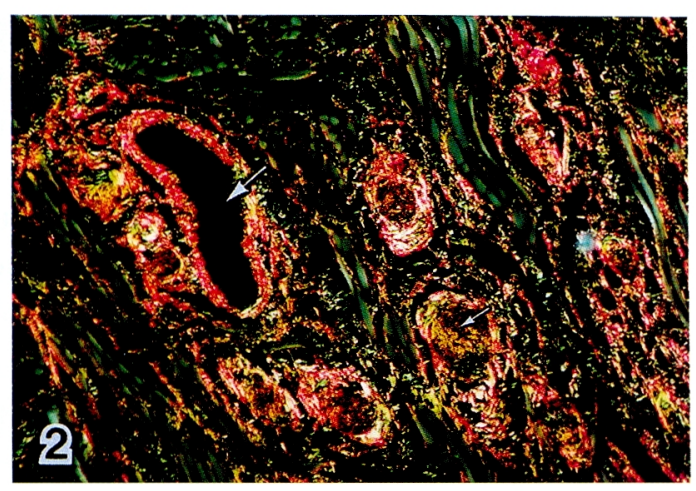

Fig. 2 Polarized light microscopic view of the capillary (large arrows) surrounded by different types of collagen fibers and nerve fiber bundles (small arrow). Picro-Sirius $\times 125$.

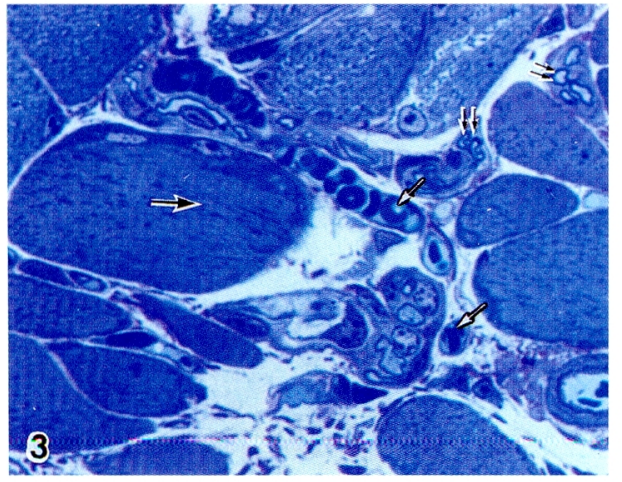

Fig. 3 Shows the muscles fibers (large arrow), capillaries (small arrow) and myelinated nerve fibers (two arrows). Toluidine blue $\times 670$.

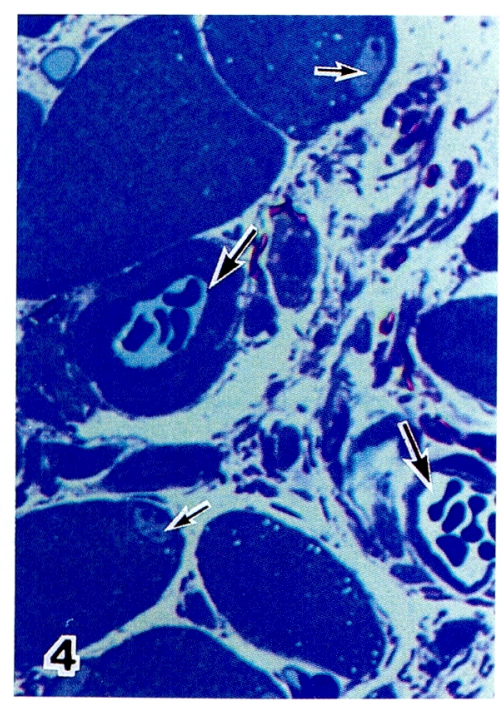

Fig. 4 Note the capillaries between of the muscle fiber bundles (large arrows) and the nuclei of muscle cells (small arrows). Toluidine blue $\times 670$. diameters varied from 60 to $130 \mu \mathrm{m}$ and they ramified and anastomosed widely. The capillary network was complex, presenting gauges from 3 to $10 \mu \mathrm{m}$ (Fig. 7). The collagen fibers were removed and the smooth muscle cells from the blood vessels observed, through the HCl-collagenase method. The smooth muscle cells were disposed in parallel lines and in a circular way. A bundle of nerves adhering to the musculature medium layer was observed (Fig. 8). The arterial blood vessel, macerated in $\mathrm{NaOH}$, presented longitudinal striations and elongated impressions from

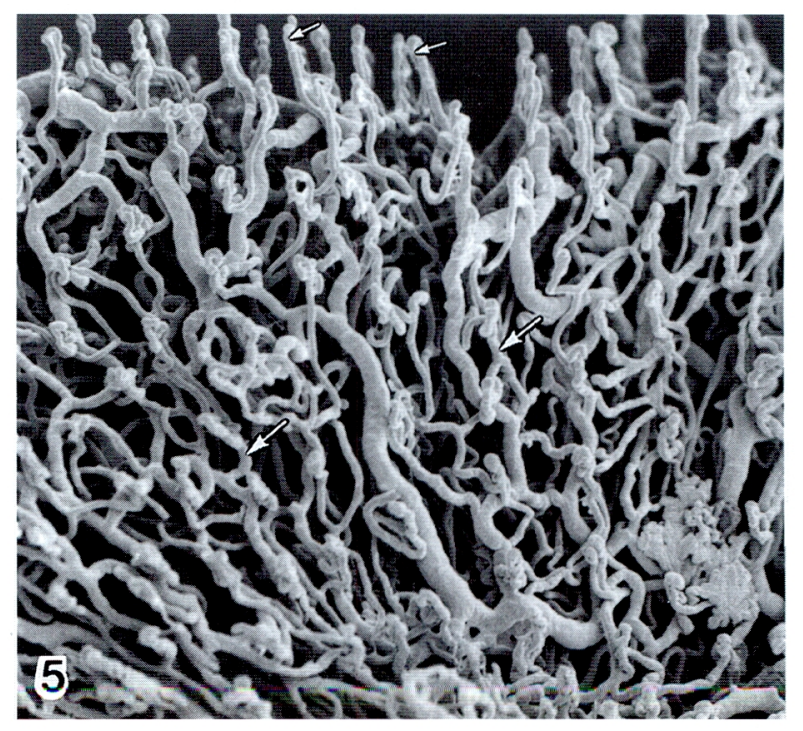

Fig. 5 SEM image of a vascular cast of the specimens treated with $\mathrm{NaOH}$ solution. Shows the capillaries of the deep layer (large arrows) and the superficial projection of the capillary network (small arrows). $\times 88$.

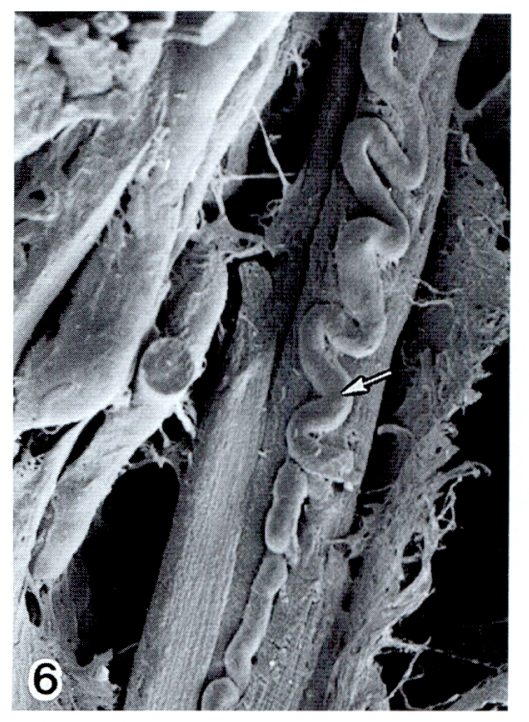

Fig. 6 Note the tortuous direction of the capillary (arrow) in the muscle fibers fractured longitudinally. $\times 500$. 
the endothelial cells with greater length than width, having approximately $19 \mu \mathrm{m}$ long and $8 \mu \mathrm{m}$ wide (Fig. 9). The venous capillaries drained into a higher-gauge vein, which was characterized by round impressions of the endothelial cell nuclei (Fig. 10). The surfaces of fractured muscle fibers, revealing the collagen fibers of the endomysium and interposed capillary, were observed in three-dimensional HRSEM images. The blood capillaries emerged among the

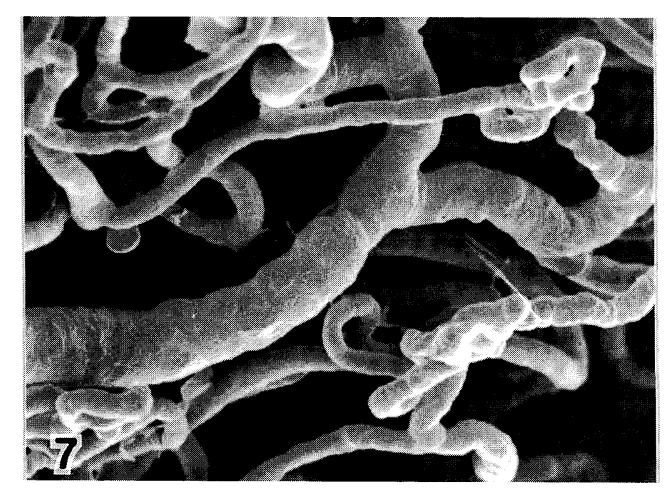

Fig. 7 Shows the capillaries forming a dense interlacing network at deep layers of the tongue, with diameters varying from 3 to $10 \mu \mathrm{m} . \times 228$.

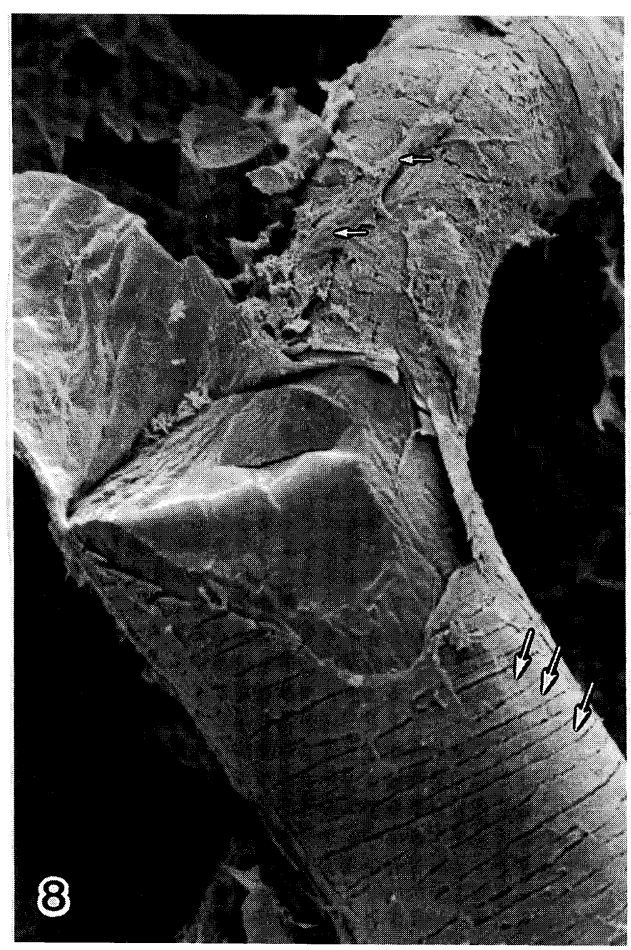

Fig. 8 SEM image of a specimens treated with $8 \mathrm{~N} \mathrm{HCl}-$ collagenase. The surface shows of the smooth muscle cells disposed in concentric arrangements (large arrows), and the bundles of nerve fibers running along the surface of the capillary are seen (small arrows). $\times 628$. muscle fibers enveloped by collagen fiber bundles (Fig. 11). These capillaries, having numerous sinuousities, were parallel to the muscle cells, with reticular collagen fibers of the endomysium enveloping both structures (Fig. 12). The capillary surface was in juxtaposition with the muscle fiber basal lamina, showing ramification (Fig. 13), and the basal lamina showed reticular fibers on the sarcolemma and capillary surfaces (Fig. 14).

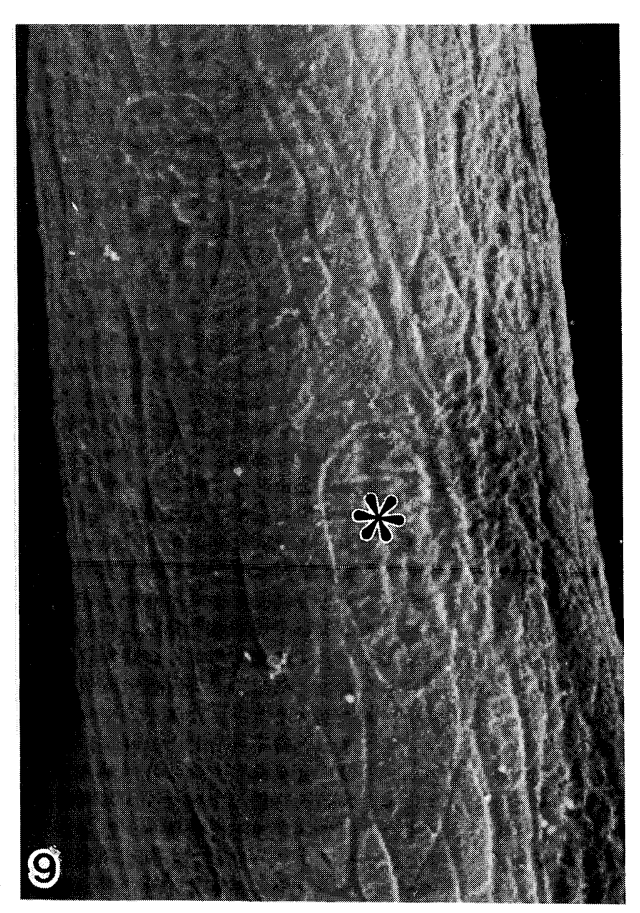

Fig. 9 At high magnification, on the surface of the arteriolae the endothelial cell nuclei is imprinted as oval in shape $(*) . \times 1,885$.

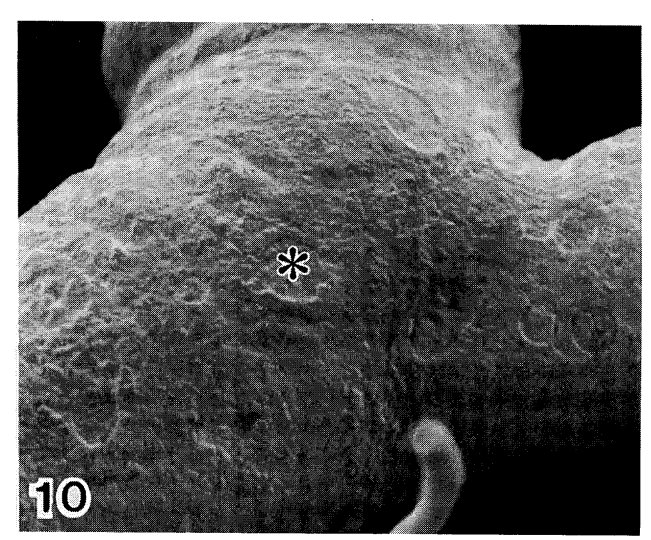

Fig. 10 The nuclei of endothelial cells of vein show circular depressions $(*)$. $\times 817$. 


\section{Discussion}

Our results showed that the anterior third of the tongue is highly vascularized, and the arteries penetrate the deep layer of the musculature, ramifying parallel to the bundle of the muscles. In the endomysium connective tissue, the capillaries are coiled and sinuous projecting to the superficial layer where they present capillary projections in the epithelium connective papillae, which has also been

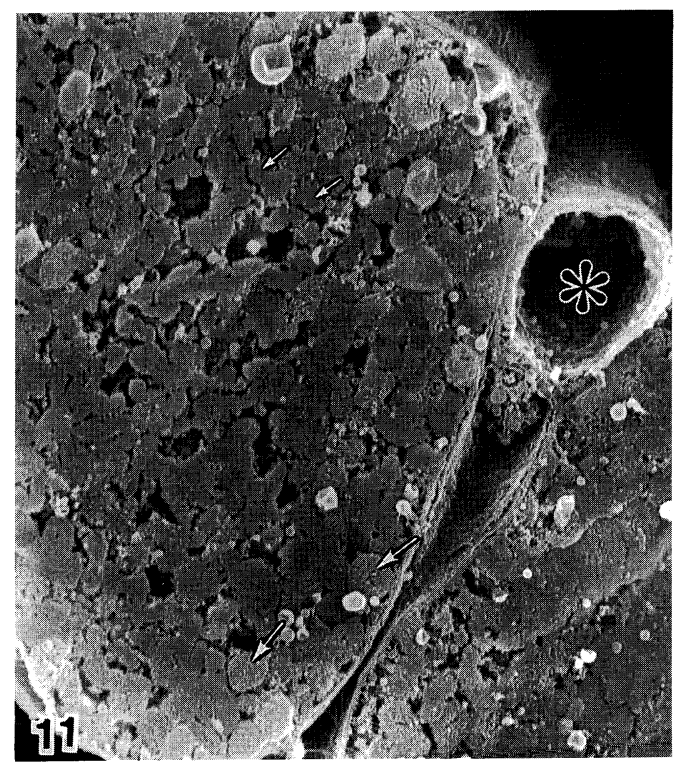

Fig. 11 HRSEM image reveals the bundles of myofilaments (small arrows), mitochondria (large arrows) and capillaries located closely to the cell membrane (*). $\times 7,000$.

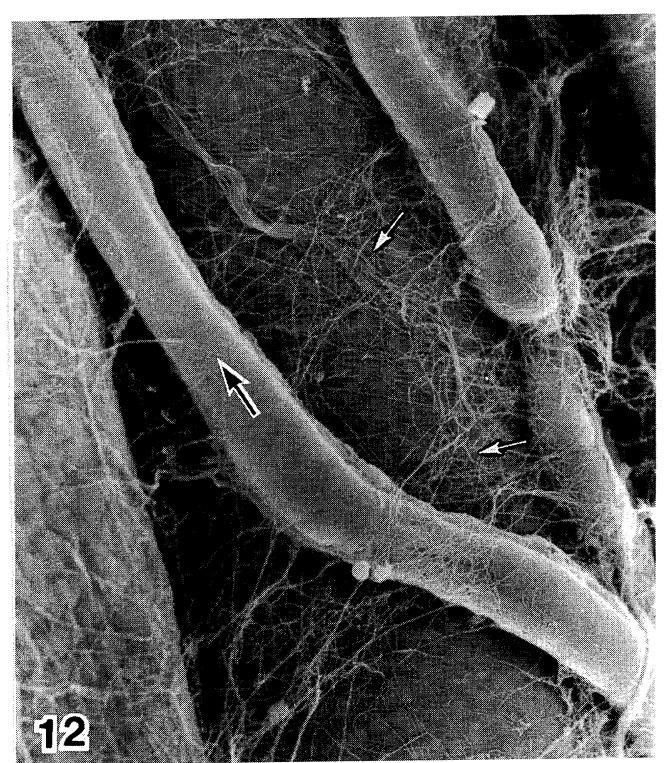

Fig. 12 Shows the capillaries in three-dimensional images (large arrows) and reticular collagen fibers of endomysium (small arrow). $\times 2,600$.

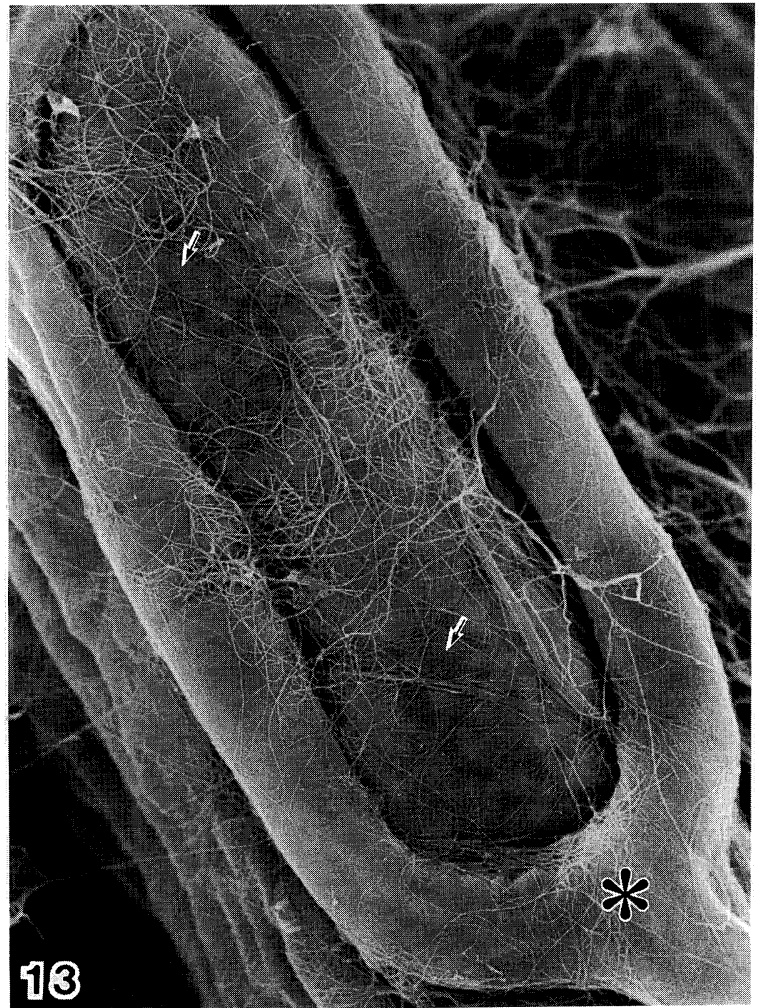

Fig. 13 Branched capillaries on the muscle cell (*) and the basement membrane are clearly seen (arrows). $\times 5,000$.

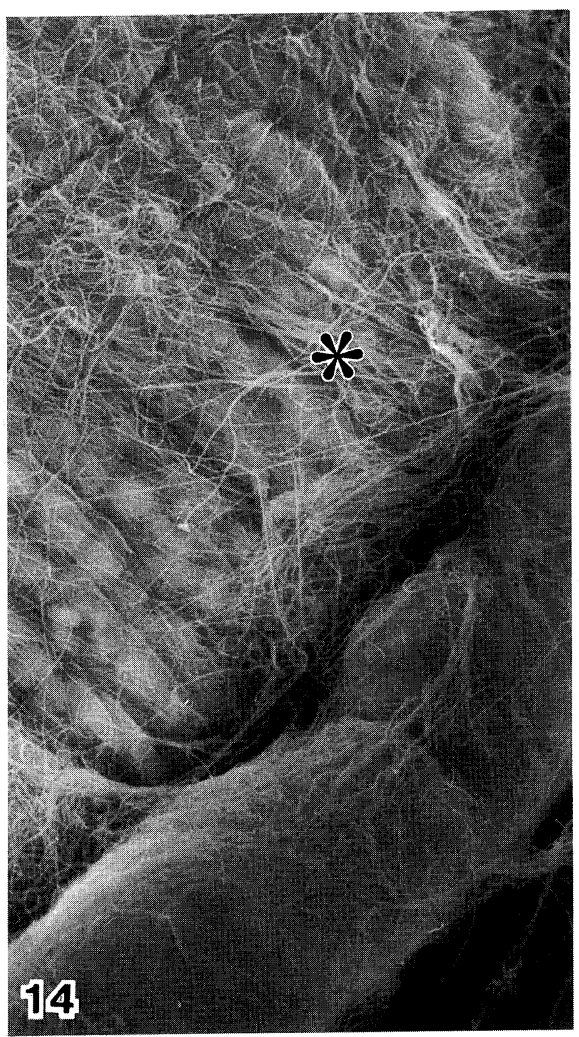

Fig. 14 High magnification shows the reticular fibers of endomysium(*). $\times 8,000$. 
observed in the primate tongue (8). In the human fetal tongue (18 to 21 weeks) three different layers have been observed: a vascular system in the lingual papillae mainly composed of capillaries, a subpapillary capillary net containing small arteriolae and veins and a deep layer in the musculature with the vessels constituting a plexus (1). It was not possible to determine, through this work, the blood flow direction or the presence of valves in venules (25), but the site of the nuclei from the endothelial cells could be clearly observed, presenting elongated impressions for the arterial capillaries and rounded in the venules, as has been reported for bone marrow (2), dog tongue (6), mammal tongue (8), rat tongue (9-11) and undernourished rat tongue (12). The capillaries showed a longitudinal extended network around and among the muscle fibers individually, composed of longitudinal and transverse segments that showed a tortuous course. The coils and sinuosities of the capillaries in juxtaposition with or among the observed muscle fibers seemed to be related to the musculature characteristic of contraction and relaxation. Thus, through this sinuosity, the vessel can fit these movements without disruption. Our data demonstrate that the dorsum of the rat tongue presents, superficially, capillaries irregularly wound and having knots, and following that, ascendant and descendant capillaries, from which the first two layers will drain into the subjacent venous plexus. Furthermore, the fourth layer contains arteriolae of the muscle layer, demonstrating that the vascular system is organized and specific, fitting the functions of this organ in the rat, which was also observed by Selliseth et al. (10). In mammals some arteriovenous anastomosis in the lingual apex and in the lamina propria can be observed, so that dense capillary chains and venules are found building up a net (8). The data also show that the arterial capillaries are coated by the smooth muscular tissue fibers involving them in a circular way and providing them with higher resistance to the passing of blood flow. After the removal of the connective tissue from the fibrous layer, bundles of nerves can be observed adhering to the medium layer, allowing stimulus of this musculature, in accordance with studies in dog's tongue (7) in which the tunica media was externally composed of a circular layer from the smooth muscle cells and internally of longitudinal plicae from the muscle cells ramifications. The samples for HRSEM $(15-17,20)$ show that the collagen fiber net in the endomysium is related to a spongy-like structure corresponding to the basal lamina from the sarcolemma which is separated through the fractured surfaces, as shown in the DMSO-method. The basal lamina structure presents some aspects similar to those observed in the frog's sartorium muscle (26) and in rat and mouse's submandibular glands $(21,27)$.

Ohtani et al. (28) in dog's tongue reported the disposition of the collagen fibrillar net as being consistent with a supportive substratum of helicoid connective tissue connected to the muscle fibers and adjacent to the blood vessels. The endomysium collagen fibers observed in HRSEM images show a three-dimensional net external to the sarcolemma basal lamina, and owing to the mechanical resistance of collagen, it uniformly distributes the tension forces during passive contraction and relaxation. The network between the muscle fibers and the capillaries contributes to structural and functional integration and through its wavy and loose aspect it could function as an elastic system absorbing impacts maintaining the blood flow in the muscular fiber (29).

\section{References}

1. Strek, P., Litwin, J.A., Nowogrodzka-Zagórska, M. and Miodonski, A. J. (1995) Microvasculature of the dorsal mucosa of human fetal tongue: a SEM study of corrosion casts. Ann. Anat. 177, 361-366

2. Ohtani, O., Gannon, B., Ohtsuka, A. and Murakami, T. (1982) The microvasculature of bone and especially of bone marrow as studied by scanning electron microscopy of vascular casts - a review. Scan. Electron Microsc. 427-434

3. Taniguchi, Y., Ohta, Y. and Tajiri, S. (1952) New improved method for injection of acrylic resin. Okajimas Folia Anat. Jpn. 25, 259-267

4. Taniguchi, Y., Ohta, Y. and Tajiri, S. (1955) Supplement to new improved method for injection of acrylic resin. Okajimas Folia Anat. Jpn. 27, 401406

5. Murakami, T. (1971) Application of the scanning electron microscope to the study of the fine distribution of the blood vessels. Arch. Histol. Jpn. $32,445-454$

6. Kishi, Y., So. S., Harada, Y. and Takahashi, K. (1988) Three-dimensional SEM study of arteriovenous anastomoses in the dog's tongue using corrosive resin casts. Acta Anat. (Basel) 132, 1727

7. Iijima, T., Kondo, T., Nishijima, K. and Tanaka, T. (1989) Innervation of the arteriovenous anastomoses in the dog tongue. Cell Tissue Res. 258, 425-428

8. Nakamura, M. and Okada, S. (1992) Microvascular architecture of the lingual papillae in the Japanese monkey (Macaca fuscata fuscata). Okajimas Folia Anat. Jpn. 69, 183-197

9. Selliseth, N.J. and Selvig, K.A. (1993) Microvasculature of the dorsum of the rat tongue: a 
scanning electron microscopic study using corrosion casts. Scand. J. Dent. Res. 101, 391- 397

10. Selliseth, N.J., Olsen, H.C. and Selvig, K.A. (1995) Effect of specimen preparation method on relative volume of the microvasculature - a light microscopic study in rat tongue. Eur. J. Oral Sci. 103, 242-246

11. Makiyama, M.C.K., Watanabe, I.S., Mizusaki, C.I. and Konig Junior, B. (1998) Three- dimensional angioarchitecture of tongue corrosion casts from normal young rats. Ann. Anat. 180, 327-330

12. Makiyama, M.C.K.,Watanabe, I.S., Mizusaki, C.I., Liberti, E.A., Lopes. R.A. and Miglino, M.A. (1998) Angioarchitectural arrangements in corrosion casts of tongue young malnourished rats. Braz. J. Morphol. $15,229-233$

13. Lametschwandtner, A., Lametschwandtner, U. and Weiger, T. (1990) Scanning electron microscopy of vascular corrosion casts-technique and applications: update review. Scanning Microsc. 4, 889-940

14. Ohta, Y., Okuda, H., Suwa, F., Okada, S. and Toda, I. (1990) Plastic injection method for preparing microvascular corrosion casts for SEM and its practical application. Okajimas Folia Anat. Jpn. 66, 301-311

15. Tanaka, K. (1980) Scanning electron microscopy of intracellular structures. Int. Rev. Cytol. 68, 97-125

16. Tanaka, K. (1981) Demonstration of intracellular structures by high resolution scanning electron microscopy. Scan. Electron Microsc. 1-8

17. Tanaka, K. and Mitsushima, A. (1984) A preparation method for observing intracellular structures by scanning electron microscopy. J .Microsc. 133, 213222

18. Junqueira, L.C.U., Cossermelli, W. and Brentani, R. (1978) Differential staining of collagens type I, II and III by Sirius Red and polarization microscopy. Arch. Histol. Jpn. 41, 267-274

19. Spurr, A.R. (1969) A low-viscosity epoxy resin embedding medium for electron microscopy. J. Ultrastruct. Res. 26, 31-43

20. Tanaka, K. (1989) High resolution scanning electron microscopy of the cell. Biol. Cell. 65, 89-98

21. Watanabe, I., Koriyama, Y. and Yamada, E. (1992) High-resolution scanning electron microscopic study of the mouse submandibular salivary gland. Acta Anat.(Basel) 143, 59- 66

22. Murakami, T. (1974) A revised tannin-osmium method for non-coated scanning electron microscope specimens. Arch. Histol. Jpn. 36, 189-193

23. Ohtani, O. (1987) Three-dimensional organization of the connective tissue fibers of the human pancreas: a scanning electron microscopic study of $\mathrm{NaOH}$ treated-tissues. Arch. Histol. Jpn. 50, 557-566

24. Evan, A.P., Dail, W.G., Dammrose, D. and Palmer, C. (1976) Scanning electron microscopy of cell surfaces following removal of extracellular material. Anat. Rec. 185, 433-445

25. Scala, G., Mirabella, N., Germano, G. and de Girolamo, P. (1992) The microvasculature of the lingual mucosa in Capra hircus. Ital. J. Anat. Embryol. 97, 177-188

26. Sawada, H., Ishikawa, H.and Yamada, E. (1978) High resolution scanning electron microscopy of frog sartorius muscle. Tissue Cell. 10, 179-190

27. Watanabe, I., Yamada, E., Kawano, Y.K. and Ogawa, K. (1994) Scanning electron microscopy of acinar cells of rat submandibular salivary glands. Braz. J. Med. Biol. Res. 27, 2197-2206

28. Ohtani, O., Ushiki, T., Taguchi, T. and Kikuta, A. (1988) Collagen fibrillar network as skeletal framework: a demonstration by cell-maceration /scanning electron microscope method. Arch. Histol. Cytol. 51, 249-261

29. Vasilev, V., Andreev, D. and Kuhnel, W. (1995) Scanning electron microscopy of the endomysial collagen in the rat paravertebral musculature. Ann. Anat. 177, 85-87 